\title{
Desigualdad, pobreza y migración en las provincias de Lima y el impacto del centralismo
}

Recibido: 14/09/2016

Aprobado: 18/10/2016

\author{
Franklin Miranda Valdivia \\ Universidad Nacional Mayor de San Marcos \\ < framirval@yahoo.es >
}

\begin{abstract}
RESUMEN
La desigualdad es uno de los problemas históricos del mundo moderno, de sus regiones y países. Las distintas formas y niveles de cómo se expresa la desigualdad inquietan los debates interdisciplinarios del desarrollo social actual y las políticas sociales consiguientes. Desde distintas perspectivas la desigualdad es abordada por el PNUD, la CEPAL en nuestra región, OXFAM en sus informes nacionales, regionales y mundiales sobre desigualdad, riqueza, pobreza y medioambiente. El capital en el siglo XXI de Thomas Piketty analiza la desigualdad histórica y propone el impuesto al patrimonio, la educación inclusiva y la seguridad social como instrumento de redistribución del ingreso. Para el caso peruano existen los trabajos sobre desigualdad de la Universidad Católica, Universidad del Pacífico y el IEP, entre otros. La desigualdad y la pobreza en el Perú de hoy se presenta en el ámbito rural andino y amazónico, afectando a grupos étnicos y lingüísticos originarios; afecta también a los afrodescendientes e inmigrantes internos en el espacio urbano de la costa. El centralismo nacional, focalizado principalmente en Lima, presenta un escenario caracterizado por desigualdades territoriales, poblacionales y de ingresos polarizantes. Estos contrastes profundizan las diferencias étnicas, sociales, raciales y económicas que limitan el desarrollo democrático permitiendo la subsistencia de una estructura social con baja movilidad social.
\end{abstract}

Palabras clave: Desigualdad, segregación, migración y centralismo

\section{Inequality, poverty and migration in the provinces of Lima and impact of centralism}

\begin{abstract}
Inequality is one of the historical problems of the modern world, its regions and countries. The various forms and levels of inequality are showing how disturbed are the interdisciplinary discussions of current social development. From different perspectives inequality is addressed by UNDP, ECLAC in our region, OXFAM in their national, regional and global reports on inequality, wealth, poverty and the environment. The book "The Capital in the Twenty-First Century" by Thomas Piketty analyzes the historical inequality and proposes the estate tax, inclusive education and social security. For the Peruvian case there are different works on inequality from the Catholic University, University of the Pacific, IEP, among others. Inequality and poverty in Peru today is more present in the Andean and Amazonian rural areas, affecting ethnic and linguistic indigenous groups; also affects people of African descent and internal migrants on the urban area of the coast. The national centralism, focused mainly in Lima, presents a scenario characterized by territorial, population and income inequalities polarizing. These contrasts make the ethnic, social, racial and economic differences worse and limit democratic development allowing the continued existence of a social structure with low social mobility.
\end{abstract}

KEYwORDs: Inequality, segregation, migration and centralism 


\section{Desigualdad y pobreza rural en el perú de hoy}

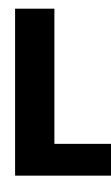
a desigualdad en el escenario real se expresa de manera compleja, diversa y cambiante, desde estas múltiples miradas el PNUD considera que la desigualdad significa: "Las privaciones conjuntas se generan cuando la desigualdad en salud y educación coincide con la desigualdad de ingresos, lo que a su vez puede superponerse con la etnia y el género. La mejor calidad de los datos sobre países en desarrollo ha facilitado la comprensión de las privaciones conjuntas, mientras que el análisis de los países desarrollados arroja patrones similares, a pesar de que, en general, hay mayor acceso a servicios públicos." (PNUD 2010: 82). Asimismo, los grupos etnolinguísticos que por razones étnicas, de lengua y de ubicación geográfica de difícil accesibilidad serán menores sus posibilidades de desarrollo.

En el contexto de América Latina y en particular del Perú la desigualdad estructural e histórica nos hace la región de mayor desigualdad en el planeta "La desigualdad es una de las principales características que definen la historia de América Latina y el Caribe (Región más desigual del mundo). Una muy alta y persistente desigualdad que, acompañada de una baja movilidad social, han llevado a la región a caer en una "trampa de desigualdad" (PNUD 2010: 7) La heterogeneidad y la fragmentación de los países que conforman nuestra región de América Latina tiene raíces históricas y son consecuencia del patrón de desarrollo desigual, como lo expresa el PNUD en su informe regional:

La aguda desigualdad que secularmente ha recorrido a América Latina y el Caribe hunde sus raíces en la historia. Se remonta a la radical negación de derechos en función de categorías raciales y estamentales que confinó a gran parte de la población del continente a la esclavitud, el sometimiento y la expropiación de recursos. En la vida republicana los privilegios siguieron reproduciéndose de otras diversas maneras, que mantuvieron asimetrías en cuanto a derechos y condiciones de vida. Finalmente, el patrón de desarrollo y modernización perpetuó las brechas socioeconómicas basadas en el origen racial y étnico, el género y la clase social. La estructura productiva y las oportunidades educativas consagraron patrones de reproducción de la desigualdad y, en gran medida, lo siguen haciendo. (CEPAL 2010: 185)

Muchas veces las comparaciones son injustas pero alec- cionadoras. En ese contexto OXFAM establece comparaciones contrapuestas, de cómo los ingresos de algunos países son menos desiguales respecto a otros, como en el caso peruano cuyas brechas son abismales:

En una sociedad verdaderamente igualitaria existiría un elevado grado de movilidad social, algo que no ocurre cuando el nivel de desigualdad económica es elevado. El profesor universitario Miles Corak ha relacionado el coeficiente de Gini y el grado de dependencia entre los ingresos de una persona y los de sus padres Por ejemplo en Dinamarca, uno de los países con un coeficiente Gini más bajo, sólo el 15\% de los ingresos actuales de un adulto joven dependen de los ingresos de sus padres; en Perú, un país con uno de los coeficientes de Gini más elevados del mundo, dos tercios de lo que gana actualmente una persona se relacionan con lo que sus padres ganaron en el pasado. Esta relación se conoce como "la curva del Gran Gatsby”, porque como dijo F. Scott Fitzgerald, los ricos "no son como tú y yo" y tampoco lo son sus hijos. (OXFAM Informe 21: 2014).

Enmarcando, en la actual coyuntura de crisis que afecta a América Latina y en particular al Perú, debido a la baja diversificación productiva y frente a la caída de los precios y menor exportación de materias primas en un mercado mundial desfavorable, que impacta negativamente en la caída de los ingresos, el desempleo, el incremento de la corrupción, mayor inestabilidad política, etc. se mantendrá y se profundizará la desigualdad prosiguiendo infortunadamente su raíz histórica. La CEPAL en estudios recientes sobre América Latina dice:

La desigualdad es una característica histórica y estructural de las sociedades latinoamericanas. Su manifestación más elocuente es la distribución del ingreso, que constituye, a la vez, la causa y el efecto de otras desigualdades en ámbitos tales como la educación y el mercado de trabajo. La matriz de la desigualdad social en América Latina y el Caribe está fuertemente condicionada por la estructura productiva, pero también por determinantes de género, raza y etnia, que se entrecruzan y se potencian. Entender esos determinantes, sus magnitudes e interrelaciones es fundamental para formular políticas que permitan avanzar hacia la igualdad. (CEPAL: 2015: 22).

La áreas geográficas de difícil acceso, escenario de resistencia milenaria de las culturas originarias especialmente de países de la subregión andina, y en particular 
el Perú, continuaran con la brecha histórica de desigualdad no obstante su ciclo de alto crecimiento con poco desarrollo, como precisa la CEPAL:

A pesar de los avances logrados en la reducción de la pobreza y de la desigualdad de ingresos, siguen arraigadas profundas disparidades entre distintos segmentos de la población y áreas geográficas de los países. La pobreza, la indigencia y la vulnerabilidad están fuertemente marcadas por los determinantes de género, raza y etnia, así como por determinados momentos del ciclo de vida, como la infancia, la juventud y la vejez. También son muy pronunciadas la heterogeneidad y las desigualdades regionales en el interior de los países y entre las zonas rurales y urbanas, y persisten importantes brechas en la región en todas esas dimensiones. (CEPAL 2015: 25)

Los grupos sociales más vulnerables por razones de edad son los niños y niñas por un lado y las personas adultas mayores por otro. Nos referiremos en este informe particularmente a la situación de vulnerabilidad de la niñez que según INEI en estudios recientes sobre pobreza, manifiesta que: "En el año 2014, la pobreza afectó al 33,6\% de las nińas y los niños menores de cinco ańos de edad, al 34,2\% de los que tienen de 5 a 9 años de edad, al 32,8\% de los de 10 a 14 años y al 23,4\% de los adolescentes de 15 a 19 años de edad. En el resto de los grupos etarios, la incidencia de la pobreza es menor al promedio nacional" (INEI, 2015: 45). Esto significa que en promedio la pobreza monetaria afecta a la niñez en aproximadamente en un tercio; mientras que cerca de una cuarta parte de los adolescentes del país viven en situación de pobreza.

Asimismo, la situación de desigualdad y pobreza histórica continúa afectando con mayor incidencia a quienes conforman las comunidades originarias de descendencia quechua, aimara y de otras lenguas amazónicas, como resalta el Informe del INEI:

Analizando la incidencia de la pobreza según la lengua materna de las personas, se observa que afecta más a la población que tiene como lengua aprendida en su nińez una lengua nativa: quechua, aimara o lenguas amazónicas. Así, en el año 2014, la pobreza afectó al $35,4 \%$ (8,5\% pobre extremo y $26,9 \%$ pobre no extremo) de las personas que mencionaron tener como lengua materna una lengua nativa, siendo casi el doble de la incidencia en la población con lengua materna el castellano, $19,5 \%$ (3,3\% pobre extremo y $16,2 \%$ pobre no extremo). (INEI 2014: 48)
La autopercepción de los grupos etnolingüísticos es diverso como añade el mencionado Informe del INEI:

Según el origen étnico, la pobreza tiene mayor incidencia en la población que se auto percibe de origen nativo (quechua, aimara u origen amazónico) afectando al $26,8 \%$, le sigue la población afro descendiente (negro/mulato o zambo) con 19,3\%. Entre los que se definen de origen blanco, la incidencia de la pobreza alcanzó al 18,5\% y los mestizos al 14,1\%. (INEI 2014: 50)

¿A quiénes afecta la desigual y a su vez quiénes son sus protagonistas en el Perú de ahora? La desigualdad afecta a muchos grupos sociales y diversos entre los que da a conocer OXFAM Perú:

La desigualdad, entendida como aquellas diferencias injustificadas e injustas en el acceso a recursos y oportunidades, excluye a millones de peruanas y peruanos que viven con derechos recortados. Desigualdad es la niña o el niño de una zona rural (también de una zona urbana pobre) que no recibe educación de calidad. Desigualdad es la trabajadora, que, pese a su buen desempeńo y esfuerzo, percibe menos que sus colegas hombres. Desigualdad, continua el informe, es el pequeño contribuyente que soporta una pesada carga, mientras que sectores privilegiados disfrutan de dispensas y exoneraciones. (OXFAM 2016: 1).

\subsection{Persistencia de la desigualdad y pobreza rural andina}

En estudios recientes, así como los precedentes sobre la situación agraria, pobreza, de la Encuesta Nacional de Salud (ENDES) y la Encuesta Nacional de Hogares (ENAHO) confirman que la zona rural y en particular la región andina es considerada la más pobre; esto como si se hablase sobre una región natural de "pobreza” y en razón a esta geografía de la pobreza, INEI en su Informe nos dice: "Para el año 2014, el 76,0\% de la población del país reside en el área urbana y el 24,0\% en el área rural. Si bien la población rural representa una cuarta parte de la población total, concentra al $48,8 \%$ de los pobres del país".

A nivel de región natural, el 48,1\% de los pobres del país están concentrados en la Sierra, seguida por la Costa que alberga al $34,5 \%$ y la Selva el $17,4 \%$. Los pobres extremos se concentran en el área rural del país, llegando al 82,3\%. Según regiones naturales, el $69,7 \%$ del total de los pobres extremos se encuen- 
tran en la Sierra, el 18,4\% están en la Selva y solo el $11,9 \%$ en la Costa. Estos resultados nos muestran los cambios en la composición demográfica y en la distribución urbano-rural de la población en situación de pobreza y de extrema pobreza, por la diferente naturaleza que caracteriza a estos contextos geográficos. (INEI 2014: 52)

El INEI (2015) en el Mapa de pobreza provincialy distrital 2013, en base a la referencia de 1943 distritos estudiados da a conocer que "... se tiene 484 distritos cuya incidencia de pobreza total es mayor al $60 \%$, asimismo, 840 distritos tienen incidencia de pobreza total menor al 40\%”. Por otro lado, en dicho estudio teniendo en consideración el escenario territorial en términos de regiones naturales precisa: "A nivel de región natural, se tiene en la Sierra 361 (30,2\%) de 1194 distritos con pobreza mayor a $80 \%$, así también en la Selva 67 (22,6\%) de 296 distritos y la Costa 36 (9,9\%) de 364 distritos." (INEI 2015: 50)

Actualmente de los 20 distritos más pobres del Perú, 19 se ubican en la sierra y uno en la selva. Los departamentos que figuran con mayor proporción de pobres son: La Libertad con siete distritos (Curgos, distrito más pobre a nivel nacional), Condormarca, Bambamarca, Ucuncha, Huaso, Taurija, Sitabamba. Cajamarca los distritos de José Sabogal, José Manuel Quiroz, Chetilla, Miracosta y Choropampa, La Libertad de Pallán y La Ramada. En el departamento de Ayacucho los distritos de mayor pobreza son Pucacolpa, Sarhua y Huaya. El departamento de selva Amazonas, el distrito de El Cenepa aparece como el más pobre. En Apurímac, el distrito de Huayana es el más pobre. Finalmente, en el departamento de Lambayeque, el distrito serrano de Cañaris completa la veintena de los más pobres del Perú de hoy. De acuerdo a estos estudios los más pobres de los distritos de Huancavelica y Huánuco complementar la región de la pobreza o "mancha india".

\subsection{Entre pobreza y riqueza distrital}

De manera contrapuesta, en el Mapa de pobreza provincial y distrital 2013, aproximadamente 20 distritos aparecen como los distritos más ricos o con menor incidencia de pobreza en el país. Entre estos tenemos a diez que se encuentran en Lima Metropolitana: Santiago de Surco, San Miguel, Los Olivos, Lima, La Molina, Jesús María, Pueblo Libre, San Borja, Miraflores, San Isidro y La Punta (Callao). En el departamento de Ica los distritos de Pueblo Nuevo, Chanquillo y Marcona; en Arequipa el distrito de Yanahuara y Arequipa; en Madre de Dios el distrito de Madre de Dios y Fitzcarrald; el distrito de Huanchac en el Cusco. Finalmente, el distrito de Pacocha en Moquegua. (INEI, 2015).

TABLA 1

DISTRITOS DEL PERÚ CON MÁS ALTO Y MÁS BAJO IDH 2012

\begin{tabular}{|c|c|c|c|c|c|}
\hline \multicolumn{5}{|c|}{ IDH más alto y más bajo en los distritos del Perú } & $\begin{array}{l}\text { Tabla } \\
\text { sinopsis } 1\end{array}$ \\
\hline Distritos & IDH & $\begin{array}{l}\text { Ingreso familiar } \\
\text { per cápita' }\end{array}$ & $\begin{array}{l}\text { Educación } \\
\text { actual }^{2}(\%)\end{array}$ & $\begin{array}{l}\text { Educación } \\
\text { pasada }^{2} \text { (años) }\end{array}$ & $\begin{array}{l}\text { Esperanza de } \\
\text { vida (años) }\end{array}$ \\
\hline $\begin{array}{l}\text { Miraflores } \\
\text { (Lima) }\end{array}$ & 0,7971 & 1589 & 90 & 14,2 & 79,4 \\
\hline $\begin{array}{c}\text { Chugay } \\
\text { (La libertad) }\end{array}$ & 0,0932 & 103 & 7 & 2 & 77,4 \\
\hline
\end{tabular}

\section{FIGURA 1 \\ CONTRASTE ENTRE PROVINCIAS CON MAYOR Y MENOR IDH 2012}

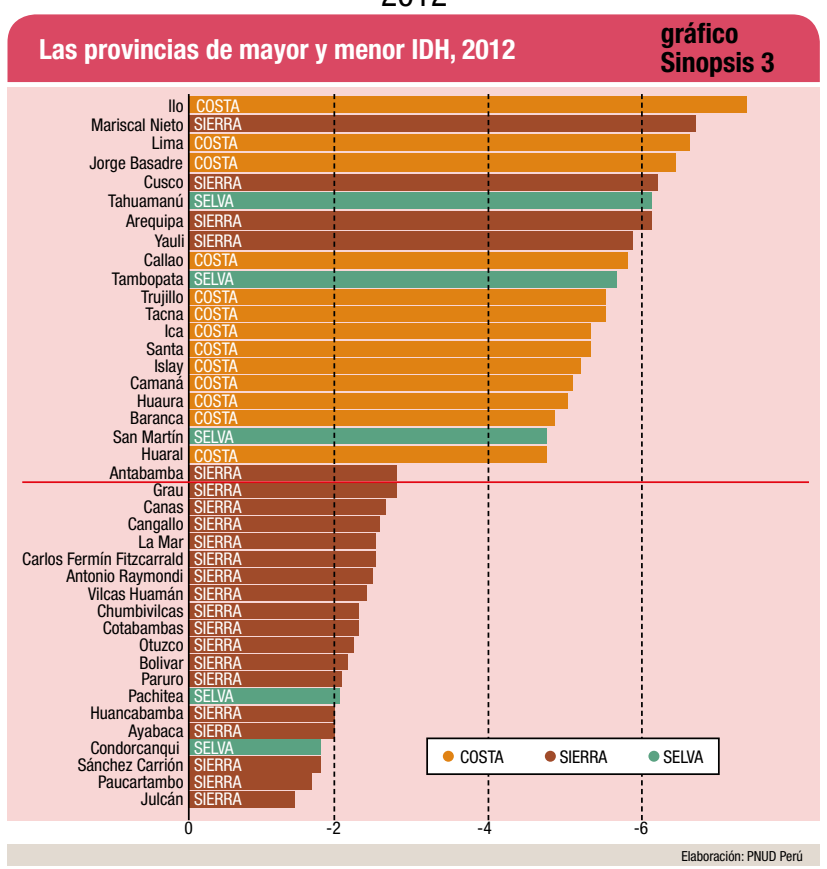

El PNUD en su Informe sobre desarrollo humano 2014, da a conocer la desigualdad abismal entre dos distritos del país: Miraflores en Lima Metropolitana, de un alto desarrollo humano presentando un IDH de 0,7971; ingreso familiar per cápita de 1589 soles; educación secundaria de $90 \%$; promedio de años de educación de 14,2 años y una esperanza de vida de 79,4 años por un lado. Por otro lado, de manera contrapuesta tenemos al distrito de Chugay, (La Libertad) con el menor desarrollo humano IDH de sólo 0,0932; un ingreso familiar per cápita también precario de sólo 103 soles; la educación secundaria alcanza al 7\%, que implica muy baja escolaridad y sin escolaridad por 
cierto; el promedio de años de educación es casi inexistente que llega apenas a 2 ańos; finalmente una esperanza de vida relativamente alta de 77,4 años, pero con baja calidad de vida que les permite una sobrevivencia o "morir a plazos".

El contexto diverso y desigual, de cómo se presenta la concentración de la riqueza en algunos espacios fundamentalmente urbanos, en contraposición de zonas pobres, se muestra en la figura 1 diseñada por el PNUD visibilizando las provincias con mayor y menor IDH hacia el 2012 en el Perú.

\subsection{Lengua materna, origen étnico y ámbito geográfico andino: Expresión de desigual y pobreza histórica}

La pobreza de la población, con lengua originaria afecta al 55\%, mientras que la de habla castellana sólo afecta al $29 \%$. La población quechua tiene $54 \%$ de pobreza y la de lengua amazónica alcanza el $81 \%$. Teniendo en cuenta la situación generacional o etaria los niños y niñas, ellas y ellos se encuentran en mayor proporción en pobreza, como da cuenta el informe de UNICEF "La situación de la nińez indígena es más grave, el 78\% de niños y niñas indígenas viven en situación de pobreza, en comparación al $40 \%$ de habla castellana. La niñez quechua alcanza una pobreza de $78 \%$ y de pobreza extrema el 48\% (Unicef 2010).

La pobreza, según lengua materna afecta más a la niñez de lengua nativa: quechua, aimara o lenguas amazónicas. Así, el año 2012, la pobreza afectó al 40,4\% de lengua nativa frente al de lengua castellana, 22,2\% estos datos denotan no solo formas de exclusión social profundas, sino también de segregación territorial.

Entonces, el color de la pobreza, es más acentuado en quienes somos cobrizos, negros o mulatos que coincide con la percepción de pobreza por origen nativo (quechua, aimara, amazónico) de 30,2\%, le sigue la población afrodescendiente (negro/mulato o zambo) con $21,1 \%$. Entre los que se definen de origen mestizo o blanco la pobreza es menor ya que incide en $17,0 \%$ y $20,6 \%$ respectivamente.

$\mathrm{Al}$ analizar, la evolución de la pobreza en el Perú estos últimos años, a través de la Figura No 2, la región natural de la sierra concentra cerca del $70 \%$ de la pobreza monetaria, la selva representa aproximadamente la quinta parte y la costa solamente el $12 \%$. La persistencia de la pobreza se presenta con mayor visibilidad en el nivel socioeconómico NSE E.
FIGURA 2

PERÚ: LOCALIZACIÓN POR REGIONES NATURALES DE LA POBLACIÓN EN POBREZA EXTREMA, 2014 (DISTRIBUCIÓN TERRITORIAL)

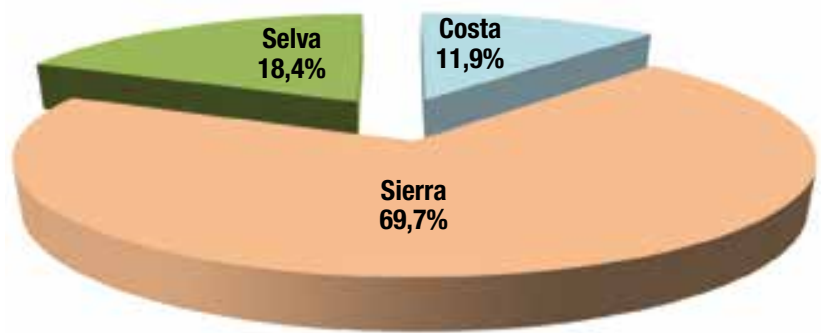

Fuente: Instituto Nacional de Estadística e Informática- Encuesta Nacional de Hogares 2014. Tomado de Informe Técnico: Evolución de la Pobreza Monetaria 2009-2014, Pág. 52.

\section{Lima Metropolitana: el contraste entre mayor y menor desarrollo humano en sus distritos}

\subsection{Contraste entre mayor y menor desarrollo humano}

El centralismo, representado por Lima Metropolitana, ha generado que esta se constituya en el polo de mayor desarrollo y concentración de la riqueza del Perú estas últimas décadas, condicionado por el modelo extractivista de crecimiento con poco desarrollo, se presente como un centro urbano de grandes contrastes, con muchas o pocas oportunidades y enormes desigualdades territoriales, de provisión de servicios educativos diferentes, de salud diferenciados, de diferentes sistemas de seguridad, de saneamiento urbano y también de ingresos con grandes brechas en el escenario de Lima . La provisión de servicios públicos carece de buena calidad y de seguridad, por ejemplo en el transporte que presenta altas tasas de accidentes.

FIGURA 3

DISTRIBUCIÓN DE HOGARES SEGÚN NSE 2014 LIMA METROPOLITANA

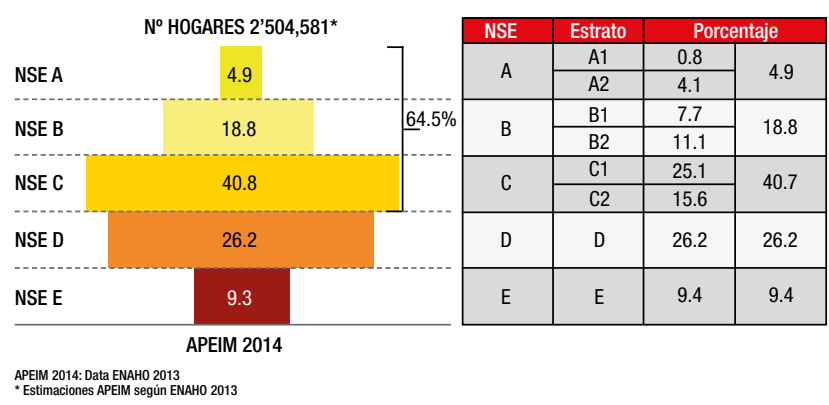

Fuente: APEMIN 2014, Niveles socioeconómicos, Pág. 10 
Respecto a los ingresos en Lima Metropolitana, presentamos los datos de APEMIN donde se muestra escenarios y espacios económicos muy diferenciados en los muchos distritos de nuestra capital (ver Figura 3).

En relación a la metodología y su validez para entender la estructura socioeconómica del Perú, el actual representante de IPSOS-Apoyo, Alfredo Torres, manifiesta que:

La APEMIN acaba de publicar su estimado para el 2013 sobre la base de los resultados de la ENAHO 2012, recientemente divulgados y sus resultados confirman, que la estructura socioeconómica del Perú, tiene la forma de una pirámide: NSE A: 2\%; NSE B: 9.4\%; NSE C: $23 \%$; NSE D: $27.2 \%$; NSE E: $38.4 \%$. Pero permite apreciar también que existen grandes diferencias según el ámbito geográfico. Por ejemplo, si se investigan sólo las 14 grandes ciudades, donde reside la mitad de la población nacional, los NSE ABC suman 55\% de la población. En cambio, si se investiga en la otra mitad del país, es decir las poblaciones más chicas y el sector rural, los NSE ABC suman $15 \%$ de esa población. (Torres 2013:10).

La desigualdad poblacional y territorial en el ámbito urbano de Lima Metropolitana presenta graves contrastes que conlleva no solo manifestaciones de desigualdad en sus 43 distritos que corresponden a la provincia de Lima y seis distritos de la provincia y región Callao; sino también rasgos evidentes de segregación urbana, que profundizan las diferencias étnicas sociales, raciales y económicas. La segregación espacial urbana expresada en la apropiación territorial de distritos de mayor desarrollo y zonas exclusivas de playas del litoral limeño privatizadas de facto, en la construcción anticonstitucional de "muros y/o cercos de seguridad" al igual que las barreras arquitectónicas contra las personas con discapacidad, pero sobretodo las barreras mentales de discriminación étnico racial, que aparecen como privilegios de "notables" o de superioridad" que empobrece y ensombrece nuestra precaria democracia y nuestra dignidad.

A propósito de la desigualdad, la BBC reporta, sobre este problema, que en Lima existen las dos caras de la moneda, donde "Las casas pueden costar más de US\$ 5 millones en esta zona y cuentan con una vista privilegiada de toda la capital del Perú. Al otro lado, crecen los pueblos jóvenes (villa miserias, "invasiones" —barrios que surgen espontáneamente sin permiso ni planificación-) de Pamplona Alta, en el distrito de San Juan de Miraflores, que no tienen ni luz ni agua. En estos lugares una casa armada con plásticos y madera puede costar menos de US\$300" (BBC Mundo, oct 2015a). También respecto al uso del agua, la desigualdad es brutal, los pobres pagan mucho más que los ricos. "En Lima, la ciudad de América Latina, donde los pobres pagan diez veces más por el agua... Una de las paradojas más crueles de la desigualdad en Lima, desde el punto de vista de los pobres, es lo barato que a menudo parece salirles a los ricos el costo de la vida" (BBC Mundo, oct 2015b).

Uno de los aspectos, que amenazan seriamente el desarrollo urbano, es la apropiación y/ o confiscación de tierras de alta productividad natural del suelo, que se ubican en las cuencas más productivas, que han dado paso a la urbanización irresponsable, que implica a su vez la disminución del pulmón verde, que disminuya el impacto ambiental y mejore las condiciones de sostenibilidad urbana de Lima Metropolitana. Frente a esta situación, el desarrollo metropolitano requiere, urgentes medidas de recuperación de áreas verdes e implementación de reforestación, la recuperación y limpieza de los recursos hídricos y de las cuencas de los ríos Rímac, Chillón y Lurín, contaminados como nunca en su larga historia de vida. También dentro del plan de desarrollo urbano, es necesario mejorar el parque automotor contaminante, por uno más limpio, rediseńo y relocalización de áreas para el desarrollo industrial.

El deterioro de la calidad de vida urbana de la ciudad de Lima, es alarmante debido a múltiples factores como la siembra irresponsable de cemento, la deforestación haciéndola más vulnerable a la contaminación ambiental y la carencia de lluvias. Esto redunda, en la negación al derecho al desarrollo de los distritos pobres, el derecho a una buena educación, a servicios de salud adecuados y de calidad; así como al derecho a la seguridad urbana. Asimismo, al acceso a buena información y participación ciudadana; es decir, el derecho a la ciudad que valore también el ámbito estético de su infraestructura, acorde a las condiciones del paisajismo natural. Es más, de acuerdo a la OMS Lima se ubica, como la segunda ciudad de mayor contaminación en América Latina al 2015, figurando Santa Getrudes en Brasil en primer lugar y Monterrey, México, en tercer lugar

La lectura de estas brechas, que se acentúan podemos observar en los datos proporcionados por el 
TABLA 2

MAYOR Y MENOR DESARROLLO HUMANO DE LOS DISTRITOS MÁS REPRESENTATIVOS DE (12) LIMA METROPOLITANA 2012

\begin{tabular}{|c|c|c|c|c|c|c|}
\hline \multicolumn{7}{|c|}{ Distritos de mayor Desarrollo Humano IDH 2012} \\
\hline Provincia/ distrito & Población & IHD & $\begin{array}{l}\text { Esperanza } \\
\text { de vida }\end{array}$ & $\begin{array}{l}\text { Educación } \\
\% \\
\text { Secundaria }\end{array}$ & $\begin{array}{l}\text { Años de } \\
\text { educación }\end{array}$ & $\begin{array}{l}\text { Ingreso } \\
\text { familiar } \\
\mathrm{S} /\end{array}$ \\
\hline $\begin{array}{l}\text { LIMA } \\
\text { Metropolitana }\end{array}$ & 9450585 & 0,6340 & 78,75 & 80,90 & 10,75 & 1017.0 \\
\hline Lima & 8481415 & 0,6417 & 79,02 & 79,09 & 10,93 & 1049,2 \\
\hline Callao & 969170 & 0.5863 & 79.16 & 81,01 & 10,36 & 822.6 \\
\hline Miraflores & 84473 & 0.7971 & 79.41 & 89.50 & 14.25 & 1589.1 \\
\hline La Molina & 157638 & 0.7814 & 79.38 & 86.20 & 13.76 & 1557.5 \\
\hline Lince & 52961 & 0.7670 & 79.49 & 85.74 & 12.85 & 1534.4 \\
\hline San Isidro & 56570 & 0.7638 & 79.46 & 88.89 & 14.02 & 1418.7 \\
\hline Jesús María & 71364 & 0.7572 & 79.51 & 85.62 & 13.42 & 1442.0 \\
\hline La Punta-Callao & 3793 & 0.7636 & 79.19 & 87.27 & 13.23 & 1484.9 \\
\hline \multicolumn{7}{|c|}{ Distritos de menor Desarrollo Humana IDH 2012} \\
\hline Pucusana & 14403 & 0.4974 & 77.62 & 60.94 & 8.84 & 623.9 \\
\hline Pachacamac & 102691 & 0.5447 & 77.87 & 66.50 & 9.93 & 767.8 \\
\hline Cieneguilla & 38328 & 0.5615 & 77.97 & 79.22 & 10.08 & 762.3 \\
\hline Carabayllo & 267961 & 0.5624 & 78.20 & 73.25 & 10.26 & 783.6 \\
\hline Puente Piedra & 305537 & 0.5679 & 78.36 & 74.21 & 10.26 & 798.5 \\
\hline Ventanilla-Callao & 370517 & 0.5315 & 78.53 & 73.32 & 10,47 & 655.1 \\
\hline
\end{tabular}

Fuente: PNUD (2014) IDH Departamental, provincial y distrital 2012

INEI (2015) Estado de la Población 2015 (Estimación población 2015)

INEI y UNFPA Perú, en "Mapa de la pobreza provincial y distrital 2009", en el que por ejemplo los distritos cuya incidencia de pobreza es muy bajo o casi inexistente son San Isidro, Miraflores y La Molina que en promedio alcanzan sólo el $0,7 \%$ en contraste a Puente Piedra, Pachacamac y Lurín que alcanzan un promedio de pobreza de $35,6 \%, 32,9 \%$ y $30,2 \%$ respectivamente.

La provincia Constitucional del Callao, según informe del INEI (2012), tiene una población estimada hacia el 2015 de 969170 habitantes, correspondiéndole al distrito del Callao 417,622 habitantes, 43\% de la población de la provincia (7 ránking de distritos del país) y Ventanilla con 370517 habitantes, 38\% de la población provincial ( 9 ranking), estos dos distritos albergan el $81 \%$ de la población del Callao. Analizando el Índice de Desarrollo Humano de esta población se observa que Ventanilla aparece con un IDH bajo con 0.5315 , en el ránking distrital se ubica en el 171 lugar cuyo ingreso familiar es de sólo S/ 655.1, contrastando abismalmente con el distrito de La Punta que sólo tiene 3798 habitantes, cuyo IDH alcanza a 07636 (6 ránking nacional) con ingresos relativamente altos que alcanzan a S/ 1484.9 (8 en el ránking de ingresos).

\subsection{Escenario de contrastes:}

Desigualdad y pobreza provincialy distrital en la Región Lima-Provincias

La desigualdad y pobreza, en las provincias y/o distritos rurales andinos de Lima provincias, también manifiestan grandes polarizaciones y contrastes, como podrá observarse por ejemplo en la provincia de Canta los distritos de mayor pobreza son Lachaqui y Humantanga con $51,3 \%$ y $41,3 \%$ respectivamente. Otra de las provincias muy heterogéneas y de grandes contrastes, en el ingreso y pobreza tenemos a Huaral con promedio de pobreza monetaria de $22,9 \%$, sin embargo posee distritos con mayor pobreza como son, los distritos andinos de Sumbilca, Atavillos Alto y Pacaraos con el $45,9 \%$ el primero, en contraste con niveles relativamente bajos de pobreza, se encuentran los distritos de costa como Aucallama, Huaral y Chancay que en promedio tienen $20 \%$ de incidencia en pobreza.

La cuarta provincia con mayor nivel de pobreza después de Yauyos, Cajatambo y Oyón es la provincia andina de Hurochirí que alcanza a 29,6\% de pobreza; siendo sus distritos de mayor pobreza los San Juan de Iris, San Antonio y Huachupampa que en promedio sobrepasan los 57\% de pobreza monetaria. Así como las provincias y distritos de Huancavelica son los más desiguales y pobres del país; los distritos de Tupe, Yauyos y Quinches, de la provincia de Yauyos, alcanzan el $64,3 \%, 62,8$ y $56,3 \%$ de pobreza respectivamente. La provincia de Yauyos aparece con mayor nivel de pobreza entre las provincias de Lima, pues alcanza el $41,8 \%$. Estas provincias andinas combinan su pequeña producción campesina con una agricultura de subsistencia a través de productos como el maíz, la cebada, las papas, el olluco y cereales andinos.

Una provincia, que es relativamente homogénea pero tiene ciertos contrastes en el ámbito de pobreza es Cañete, cuya pobreza en promedio alcanza el 26,6\%; la alta pobreza afecta sólo a los distritos de Pacarán e Imperial con $41,1 \%$ y $34,3 \%$ respectivamente. A diferencia de los distritos costeros de Calango y Asia que alcanzan en promedio el $10 \%$ de pobreza. Dentro de este ámbito, podemos ubicar también, a la provincia de 
Huaura, cuyos distritos de mayor pobreza son, los distritos andinos de Ambar, Checras y Santa Leonor que en promedio alcanzan el 35\% de pobreza, en contraste a sus distritos de costa de Huacho y Sayán que alcanzan solamente un promedio de $15,8 \%$ de pobreza.

Debemos destacar, que la provincia costeña que presenta mayor homogeneidad, respecto a la situación de baja pobreza es la provincia de Barranca, que en promedio alcanza el 20,4\%. Sin embargo las ciudades de Cañete y Barranca, ocupan el $2^{\circ}$ y $3^{\circ}$ lugar en índices de violencia (asesinatos) después de Tumbes, con 30 y 25 asesinatos por 100 mil, el año 2014 .

\subsection{Polarización y segregación territorial: riqueza y pobreza provincias de Lima}

La pobreza tiene mayor presencia en el ámbito rural y en particular el andino y amazónico. Según el INEI hacia el 2012 en el área rural viven $51,8 \%$ de los pobres y el 48,2\% en el área urbana. La sierra alberga el 49,0\%, la costa $34,7 \%$ y la selva $16,3 \%$ de pobres del país. En referencia a los pobres extremos en el área rural vive $82,7 \%$ y $72,5 \%$ lo hacen en la sierra.

¿Quiénes son los más pobres en el Perú? La respuesta no tiene dudas, pues refleja la cruda realidad de la discriminación racial, como lo confirman los datos del INEI al exponer el perfil de la pobreza y etnia: "Al analizar la incidencia de la pobreza de acuerdo con la lengua materna de las personas, se observa que ésta afecta más a la población que tiene como lengua aprendida en su niñez una lengua nativa: quechua, aimara o lenguas amazónicas. Así, en año 2011, la pobreza afectó al $45,7 \%$ (13,5\% pobre extremo y $32,2 \%$ pobre no extremo) de las personas que mencionaron tener como lengua materna una lengua nativa, siendo casi el doble de la incidencia en la población con lengua materna el castellano, 24,1\% (4,7\% pobres extremos y 19,4\% pobres no extremos)" ( INEI. Evolución de la pobreza 2012:39)

Asimismo, el informe corrobora que la discriminación tiene rasgos étnico raciales, pues la pobreza es más pronunciada en los grupos originarios quechua y, aimaras, amazónicos y negros o mulatos cuya percepción de pobreza manifiesta que "De acuerdo a la autopercepción de pertenencia étnica, la pobreza incidió en mayor medida en aquellos jefas o jefes de hogar de origen nativo (quechua, aimara u origen amazónico), ya que la pobreza afectó al $31,5 \%$, le sigue los hogares con jefe de origen negro/mulato o zambo con $28,1 \%$. En los hogares cuyos jefes son de origen blanco o mestizo la pobreza incidió en menor medida (18,3\% y $18,2 \%$, respectivamente). (INEI 2012: 38)

La desigualdad y la pobreza en el Perú y en especial las poblaciones andinas, por ejemplo las ubicadas en las provincias serranas de Lima, tales como Cajatambo, Oyón, Huaura y por supuesto gran parte de las que conforman la cultura indígena andina y amazónica, tienen profundas raíces históricas y requieren un tratamiento interdisciplinario, según propone $\mathrm{R}$. Thorp: "Este libro explora la desigualdad, en particular la que sufre la población indígena andina. Su eje es la explicación de la persistencia y la profundidad de dicha desigualdad mediante la exploración, en el transcurso de varios siglos, de la dinámica de las interrelaciones existentes entre política, economía, geografía y cultura" (Thorp 2011: 13).

Estudios recientes, sobre etnicidad y desigualdad de Rosemary Thorp y Maritza Paredes en base al análisis de la ENAHO (2003) y de los estudios de A. Figueroa, sobre ingresos (2008) las desigualdades grupales por razones étnicas y de residencia rural, son realmente indignantes e inmorales. "La incidencia de la pobreza puede calcularse a partir de la encuesta de hogares... el $24 \%$ de la población indígena aparece identificada como 'extremadamente pobre' en comparación con el $6 \%$ de los 'mestizos' y pocos de la población 'blanca'. A partir del análisis de Trivelli, dice la autora, la población rural es más pobre que la urbana, tanto en indígenas como no indígenas, por igual. Pero entre los hogares indígenas, son los monolingües los 'chutos', son los que muestran los indicadores menos favorables" (Thorp, 2011: 72).

La cuestión étnica, de género y de residencia en ámbito rural es abordada de manera precisa por Rosemary Thorp, al encontrar en sus indagaciones de la desigualdad indígena es étnica, lingüística y por procedencia rural históricas, que afecta el desarrollo de los grupos indígenas, especialmente a las mujeres indígenas en sus salarios, en sus condiciones de escolaridad y acceso a la salubridad que son en menor proporción y menor calidad de los servicios de educación, salud lo cual impacta negativamente en su calidad de vida y bienestar.

La incidencia de la pobreza, en personas que tienen como lenguas originarias el quechua, el aimara y las demás lenguas amazónicas representaron, según datos del INEI del 2010, el doble de quienes tienen como lengua materna el castellano. Es decir, que la pobre- 
za afectó al 51,8\% de personas de lenguas aborígenes: mientras que a los de habla hispana sólo le afecto en $25,8 \%$. La situación de pobreza es aún más grave en el área rural tanto para personas de habla aborigen como para los de habla castellana, en el primer caso la pobreza afecta a 63,6\% y en el segundo a la mitad, 47,6 en el 2010. (INEI 2001-2010: 97)

La discriminación étnica- racial y la exclusión por lugar de residencia, aparece muy sutilmente en nuestro medio, no obstante el "desborde popular" y su impacto de democratización en la vida urbana del país es aún insuficiente, fundamentalmente por carecer de políticas de democratización cultural, educativa que permiten medios de comunicación que moldean y manipulan la conciencia popular a través de programas mediáticos distractivos, poco educativos y culturales que envilecen la mente de nuestras poblaciones.

En vista, que la información estadística es poco precisa, para explicar el origen étnico, particularmente negro/mulato/zambo, los estudios a través de entrevistas sobre la autopercepción de pobreza de este grupo, fue de 57\% el 2004 y de 30,2\% el 2010: el grupo de origen nativo, especialmente quechua, su percepción de pobreza disminuyo de 52,8\% el 2004 a 35,9\% el 2010. Esta autopercepción positiva de sentirse menos pobre en ambos grupos discriminados históricamente es positivo, pues la mejora relativa de su situación económica, sus niveles de educación incrementados, su mejoramiento en su autoestima, le ha permitido ser más protagonistas de su destino, labrado intensamente en el fragor de la dura realidad cotidiana, que muchas veces le es adversa, pero finalmente se sobreponen y avanzan.

Esta percepción coincide con la hipótesis de Rolando Arellano de "Al medio hay sitio" que los estilos de vida dan cuenta que la polarización económica entre los altos estratos y los más bajos se van redefiniendo: se incrementa la nueva clase media, muchos migrantes irrumpen la escena urbana, se apropian de ella y desplazan a quienes ostentaron el poder tradicional. También en este nuevo escenario se acercan las provincias (algunas con mayor inversión y crecimiento como Arequipa, Trujillo, Cusco) con la capital: pareciera que la pobreza disminuye, aunque la desigualdad aumenta o sigue inalterable (Arellano 2010:187).

Otro de los aspectos de la desigualdad es la variable de género, como precisa el estudio del INEI: "Uno de los fenómenos que sintetiza la desigualdad en el mercado laboral, es el hecho de que las mujeres ganan menos que los varones; las mujeres perciben el equivalente al 70,3\% del ingreso laboral masculino. Cuando esta misma relación se controla por nivel de educación, la brecha es aún más desfavorable para las mujeres con mayor educación, las que perciben, en promedio, solo el equivalente del 70,5\% del ingreso laboral masculino...”. Este tipo de desigualdad va disminuyendo sus brechas debido al incremento de la escolaridad de la mujer, al nivel de conciencia ciudadana que va desarrollando y también a la participación en el movimiento social

$\mathrm{Al}$ año 2014, el mercado laboral peruano tenía 16 millones 396 mil 400 personas, de estos 7 millones 204 mil 800 eran mujeres, de las que 6 millones 915 mil 900 estaban ocupadas y 288 mil 900 en desempleo. (INEI 2015: 312).

Finalmente, la localización de la pobreza, según ENAHO 2010, confirmando hipótesis anteriores que cuestionan los datos censales del 2007, la urbanización alcanza el $65,2 \%$ y la rural al 34,8. Pero el sector rural no obstante representar tan solo un tercio de la población total del país, concentra el $60,5 \%$ de pobres (INEI, ENAHO 2010: 99).

\section{Desarrollo humano desigual, migración y desintegración territorial provincial y regional}

\subsection{Desarrollo humano, desigualdad y pobreza en Lima-Provincias}

La lengua materna, el origen étnico y el ámbito geográfico andino son las variables más significativas y expresión de desigualdad y pobreza histórica (interrelaciones entre política, economía, geografía y cultura) (Thorp). La autora considera a las lenguas originarias andinas como el quechua y el aimara; también las lenguas amazónicas, que sobrepasan 50 variedades lingüísticas, condicionan la situación de desigualdad y pobreza histórica en el Perú. Respecto al origen étnico de la desigualdad se refiere al andino y amazónico diverso y la ubicación de ellos y ellas en las zonas especialmente rurales y por el origen étnico-racial negro o zambo que tienen residencia por lo general las zona rurales y urbanas de la costa. Los espacios geográficos que los acogen a los andinos y albergan a los afrodescendientes son las zonas urbanas y en menor medida, estos últimos tiempos, las zonas rurales costeñas

La Región Lima, a través de sus provincias: Cajatambo, Oyón, Huaura, Huaral, Huarochirí y Yauyos 
aún son escenario de reproducción social andina. Esta forma de reproducción social, tiene en las variedades lingüísticas quechuas y aimaras como el jacaru, el instrumento directo de reproducción cultural, con todas las transiciones, adquisiciones y deformaciones que puedan tener en su persistencia de continuidad. Una de las formas de continuidad y resistencia andina, se presenta en la fortaleza e identidad étnica y su reproducción de las tradiciones de tecnologías andinas, en la producción rural y en sus festividades de tradición comunales, aunque sin territorio, reproducidas en las zonas urbanas generadas por la intensidad de las migraciones hacia los centros urbanos de Lima, Barranca, Huacho, y Cañete.

Asimismo, es necesario resaltar que estas cinco últimas décadas, las zonas rurales de costa, circundantes a las ciudades de Lima, Barranca, Cañete, Huaral, Huacho albergan a los andinos migrantes y a sus descendientes que conforman más del $75 \%$ de las poblaciones urbanas, y, también a la población afrodescendiente. El departamento de Lima alberga 10 provincias y 128 distritos. Las provincias de mayor concentración urbana (Censo 2007) son: Huaura (86,4\%), Barranca $(85,3 \%)$, Cañete $(84,0 \%)$ y Huaral $(82,9 \%)$.

Las provincias andinas agrícolas, ganaderas, mineras y comerciales de más de un tercio de población rural son: Huarochirí $(32,3 \%)$, Oyón $(35,5 \%)$ y Cajatambo $(39,6 \%)$; Canta y Yauyos tienen aún un alto grado de concentración de población rural que alcanza el $52,2 \%$ y $42,8 \%$ respectivamente. Las provincias con menor desarrollo humano son Cajatambo, Yauyos, Oyón, Huarochirí y Canta; ellas ocupan los puestos 88, 79, 51, 46 y 45 respectivamente. Mientras que las provincias costeñas de Barranca, Cañete, Huaura y Huaral se ubican en los puestos 17, 18, 21 y 25 respectivamente. (Miranda, 2015:16) La pobreza y desigualdad en términos territoriales, étnicos-raciales y lingüísticos, son muchos más diversos, complejos y visibles en el ámbito de distritos y en menor proporción en las provincias. Las condiciones topográficas y de relieves de una geografía física, muy agreste y de difícil accesibilidad territorial, ha contribuido a la desigualdad social territorial.

En este marco, podemos ubicar a distritos rurales con bajo desarrollo humano e intensa pobreza, que conservan aún la tradición quechua de múltiples variedades: Copa (Cajatambo), Chocos y Tupe, variedad jacaru, (Yauyos), San Andrés de Tupicocha (Huarochirí), Checras (Huaura), Cochamarca (Oyón), Ihuari
(Huaral) y Humantanga (Canta) en los puestos 1400, 1356, 1282, 734, 692, 567, 449 de desarrollo humano respectivamente.

TABLA 3 REGIÓN LIMA: POBLACIÓN CENSADA POR ÁREA DE RESIDENCIA, SEGÚN CENSOS REALIZADOS, 1940 - 2007 ESTIMACIÓN HACIA EL $2010(\%)$

\begin{tabular}{|c|c|c|c|c|}
\hline Año & Población & Urbana & Rural & TOTAL \\
\hline 1940 & 265413 & 36,6 & 63,4 & 100,0 \\
\hline 1961 & 398681 & 43,5 & 56,5 & 100,0 \\
\hline 1972 & 491272 & 61,0 & 39,0 & 100,0 \\
\hline 1981 & 581280 & 70,6 & 29,4 & 100,0 \\
\hline 1993 & 680181 & 73,1 & 26,9 & 100,0 \\
\hline 2007 & 839469 & 81,0 & 19,0 & 100,0 \\
\hline 2010 & 894568 & 82,0 & 18,0 & 100,0 \\
\hline
\end{tabular}

Fuente: INEI - Censos Nacionales de Población y Vivienda, 1940, 1961, 1972 , 1981, 1993 y 2007. Estimaciones 2009-2012

La población censada de las provincias de la Región Lima, pasa de 265413 en 1940 a 839469 en el 2007, alcanzando un incremento en 3,2 veces: mientras tanto, la población urbana paso de 97087 a 679 765 lo hizo en 7 veces más. Por otro lado, la población rural se mantuvo igual en términos absolutos en estos 67 ańos, pero mostrando una caída intercensal considerable.

TABLA 4

REGIÓN LIMA: POBLACIÓN CENSADA, SEGÚN PROVINCIA 1981, 1993, 2007 Y ESTIMACIÓN 2015

\begin{tabular}{|l|r|r|r|r|}
\hline Provincia & \multicolumn{1}{|c|}{1981} & \multicolumn{1}{c|}{1993} & \multicolumn{1}{c|}{2007} & \multicolumn{1}{c|}{$2015^{*}$} \\
\hline Total & 581280 & 680181 & 839469 & 943839 \\
\hline Barranca & 102088 & 114051 & 139904 & 146241 \\
\hline Cajatambo & 11870 & 9475 & 8358 & 7828 \\
\hline Canta & 12305 & 10996 & 13513 & 15122 \\
\hline Cañete & 118126 & 152379 & 200662 & 233151 \\
\hline Huaral & 97343 & 126025 & 164660 & 190501 \\
\hline Huarochirí & 59792 & 59057 & 72845 & 81696 \\
\hline Huaura & 130771 & 163174 & 197384 & 219059 \\
\hline Oyón & 16685 & 17279 & 20642 & 22782 \\
\hline Yauyos & 32300 & 27746 & 27501 & 27459 \\
\hline
\end{tabular}

Fuente: INEI - Censos Nacionales de Población y Vivienda, 1981, 1993 y 2007 * Estimaciones 2015. La población de Lima Metropolitana es de 9886647 y del departamento de Lima 88907923 habitantes según el Estado de la población peruana 2015 del INEI

Las provincias, situadas en el litoral costeño de la Región Lima-Provincias, concentran mayor población que aquellas provincias ubicadas en la sierra, que son a su vez generadoras de altas tasas migratorias en beneficio de Lima y sus provincias litorales. Por ejemplo 
la provincia de Huaura, preponderantemente costeña, participa con el $23,5 \%$ del total de la población de la Región Lima el 2007. Asimismo, la provincia de Cañete y Barranca concentran el $24 \%$ y $16,7 \%$ de la población según el Censo del 2007. Contrariamente, las provincias andinas de Cajatambo, Canta, Oyón y Yauyos sólo poseen el 1\%, 1,6\%, 2,5\% y 3,2\% de población respectivamente en el mismo período Censal.

En consecuencia, podemos observar dos tendencias en la Región Lima; la primera, caracterizada por mayor concentración y consolidación de las provincias y centros urbanos ubicados en el litoral como Barranca, Huaura, y Cañete, que en conjunto representan el $64 \%$ de la población regional; la segunda, ubicadas en la zona andina de Lima que generan altas tasas de emigración especialmente de poblaciones jóvenes que provienen de Cajatambo, Canta, Oyón, Huarochirí y Yauyos, en conjunto estas cinco provincias participan, sólo el 17\% de la población en la Región Lima.

TABLA 5

REGIÓN LIMA: TASA DE CRECIMIENTO 1981-1993 Y 19932007

\begin{tabular}{|l|c|c|}
\hline Provincias & $1981-1993$ & $1993-2007$ \\
\hline \multicolumn{1}{|c|}{ Total } & 1,3 & 1,5 \\
\hline Barranca & 0,9 & 1,1 \\
\hline Cajatambo & $-1,9$ & $-0,9$ \\
\hline Canta & $-0,9$ & 1,5 \\
\hline Cañete & 2,1 & 1,9 \\
\hline Huaral & 2,2 & 1,9 \\
\hline Huarochiri & $-0,1$ & 1,5 \\
\hline Huaura & 1,9 & 1,3 \\
\hline Oyón & 0,3 & 1,3 \\
\hline Yauyos & $-1,3$ & $-0,1$ \\
\hline
\end{tabular}

Fuente: INEI - Censos Nacionales de Población y Vivienda, 1981, 1993 y 2007.

El promedio de crecimiento intercensal de la nueva Región Lima, alcanza 1,3\% en el período 1981-1993 y de 1,5\% para el período 1993-2007. Mientras, que el promedio de crecimiento negativo, representaban las provincias andinas de Cajatambo, Canta y Yauyos con $-1,9 \%,-0.9$ y -1.3 respectivamente, entre 1981-1993 y posteriormente en el período 1993-2007 Cajatambo y Yauyos presentan un acentuado decrecimiento y envejecimiento poblacional, especialmente generado por las altas tasas migratorias de jóvenes. Esta situación de la provincias serranas, contrasta con las provincias de Cańete y Huaral, que tuvieron un crecimiento de 2,2 y 2,1 en el período 1981-1993 y de 1,9 respectivamente en el período 1993-2007.
TABLA 6

DISTRIBUCIÓN DE POBLACIÓN POR PROVINCIA ENTRE 1981 Y 2015

\begin{tabular}{|l|r|r|r|r|}
\hline Provincia & \multicolumn{1}{|c|}{1981} & \multicolumn{1}{|c|}{$\%$} & \multicolumn{1}{c|}{$2015^{*}$} & \multicolumn{1}{c|}{$\%$} \\
\hline Barranca & 102088 & 17.57 & 146241 & 15.50 \\
\hline Cajatambo & 11870 & 2.04 & 7828 & 0.83 \\
\hline Canta & 12305 & 2.12 & 15122 & 1.60 \\
\hline Cañete & 118126 & 20.32 & 233151 & 24.70 \\
\hline Huaral & 97343 & 16.75 & 190501 & 20.18 \\
\hline Huarochiri & 59792 & 10.29 & 81696 & 8.66 \\
\hline Huaura & 130771 & 22.50 & 219059 & 23.21 \\
\hline Oyón & 16685 & 2.87 & 22782 & 2.41 \\
\hline Yauyos & 32300 & 5.57 & 27459 & 2.91 \\
\hline TOTAL & 581280 & 100.00 & 943839 & 100.00 \\
\hline
\end{tabular}

Fuente: INEI Censo Nacional de Población y Vivienda 1981 y estado de la población peruana 2015

Las provincias más pobladas, que están ubicadas en el litoral costeńo, hacia 1981 fueron Huaura (22.50), Cañete (20.32), Barranca (17.57) y Huaral (16.75) que en conjunto, tuvieron más del $78 \%$ de la población de un total regional de 581280 habitantes. Mientras que las provincias que se ubicaron en la sierra del departamento de Lima, como Cajatambo, Canta, Oyón, Yauyos y Huarochirí alcanzaron solamente el 22\% del total de la población regional.

Luego de casi 35 años, la población tuvo un incremento aproximado de $62 \%$, acentuándose la tendencia de incremento y desplazamiento poblacional hacia las provincias costeñas y deterioro con caída poblacional para las provincias andinas de la Región Lima-Provincias. Expresando mayor incremento en las provincias de Cańete (24.70), Huaura (23.21), Huaral (20.18) y Barranca (15.50\%) que alcanzaron aproximadamente el $84 \%$ de la población total de 943839 habitantes hacia el 2015. El incremento considerable de las poblaciones de las provincias de Cañete, Huaral, Huaura y Barranca, se debe a múltiples factores: la migración de jóvenes de las provincias serranas que forman parte del área de impacto por estas, en las cuencas altas y de provincias vecinas de los departamentos de Huancavelica, Ayacucho, Huánuco, Junín, Ancash hacia las ciudades de Cañete, Huacho, Huaral, Barranca y Supe.

Respecto al desarrollo humano, dentro de las nueve provincias que conforman actualmente la Región Lima Provincias, según el IDH 2007 divulgado en el Informe sobre Desarrollo Humano -Perú 2009, aparecen las provincias en orden de importancia que a continuación presentamos: 
TABLA 7

DESARROLLO HUMANO, ESPERANZA DE VIDA, ESCOLARIDAD E INGRESO DE LAS PROVINCIAS DE LA REGIÓN LIMA IDH 2007

\begin{tabular}{|l|r|r|c|c|c|c|}
\hline \multicolumn{1}{|c|}{ Provincia } & Población & IHD & Esperanza de vida & Alfabetismo & Escolaridad & Ingreso N. S. mes \\
\hline Perú & 27428615 & 0.6232 & 73,07 & 92,86 & 85,71 & 374 \\
\hline Lima-Callao & 8482619 & 0.6845 & 76,07 & 98,20 & 89,23 & 552,1 \\
\hline Lima & 7605742 & $0.6840(1)$ & 75.86 & 98,17 & 89,21 & $556,4(1)$ \\
\hline Lima Provincias & 839469 & 0.6281 & 73.45 & 95,31 & 88,63 & 336.7 \\
\hline Barranca & $133904(41)$ & $0.6450(17)$ & 76,24 & 94,23 & 88.00 & $364,5(25)$ \\
\hline Cajatambo & $8358(191)$ & $0.5796(88)$ & 70,92 & 89,93 & 87,66 & $204,1(105)$ \\
\hline Canta & $15513(180)$ & $0.6124(45)$ & 74,08 & 94,65 & 83,35 & $262,7(65)$ \\
\hline Cañete & $200662(21)$ & $0.6449(18)$ & 75,76 & 89,85 & 84,47 & $341,5(38)$ \\
\hline Huaral & $164660(28)$ & $0.6395(25)$ & 71,91 & 94,45 & 87,94 & $338,7(4)$ \\
\hline Huarochirí & $72845(80)$ & $0.6097(46)$ & 71,37 & 96,95 & 87,00 & $282,9(54)$ \\
\hline Huaura & $197384(22)$ & $0.6423(21)$ & 74,69 & 95,87 & 89,39 & $368,9(23)$ \\
\hline Oyón & $20642(170)$ & $0.6040(51)$ & 71,89 & 92,82 & 88,86 & $273,1(56)$ \\
\hline Yauyos & $27501(156)$ & $0.5848(79)$ & 70,17 & 94,99 & 87,99 & $189,9(123)$ \\
\hline
\end{tabular}

Fuente: PNUD, Informe sobre desarrollo humano 2009. Anexo Estadístico.

1) Provincia de Barranca, con una población de 133 904 habitantes, alcanza el puesto 17 entre el ránking de provincias en el país, su IDH 0,6450; con una esperanza de vida, que la ubica el lugar 4 del ránking respectivo con 76,24 años y también con un alfabetismo y escolaridad altos. Entre sus cinco distritos los mejor posesionados en el IDH son Barranca y Paramonga.

2) Provincia de Cañete, con una población de 200 662 habitantes, alcanza el puesto 21 en el ránking de provincias en el país, su IDH es 0,6449 que lo ubica en el puesto 18, con una esperanza de vida de 75,76 años; complementariamente gozan de un alto alfabetismo de $96,13 \%$ y alta escolaridad. Los distritos que mejor desarrollo humano presentan son San Antonio con 0,6599 y Santa Cruz de Flores con 0,65 45 en IDH. Los distritos que menor desarrollo humano, se ubican en la sierra de la provincia resaltando, Coayllo IDH 0,6258 y Pacarán 0,6309.

3) Provincia de Huaura, con una población de 197 384 habitantes (22 ránking provincias) tiene un IDH de 0,6423 que lo ubica en el puesto 21 del ránking provincial nacional del IDH, con una esperanza de vida de 74,69 años, alto alfabetismo que alcanza a $95,87 \%$ y alta escolaridad.

Huaura, es una provincia de grandes contrastes en desarrollo humano, población, producción y urbanización. El distrito y ciudad de Huacho con 55 442 habitantes alcanza un alto desarrollo humano de 0,6676 le sigue el distrito de Hualmay con
0,6539. Contrariamente sus distritos de la zona andina como Checras $(0,5804)$, Leoncio Prado $(0,5856)$ y Ambar $(0,5930)$ tienen un IDH mucho menor y una caída de población por la migración intensa.

4) Provincia de Huaral, con 164660 habitantes (28 ránking de población de provincias) tiene un IDH de 0,6395 que lo ubica en el puesto 25 del ránking provincial nacional del IDH, con una esperanza de vida de 75,91 ańos, alto alfabetismo que alcanza a $94,45 \%$ y alta escolaridad.

Huaral, presenta algunas similitudes con Huaura, provincia de grandes contrastes en desarrollo humano, población, producción y urbanización. Los distritos costeros de Chancay $(0,6438)$ y Huaral $(0,6429)$ tienen un alto IDH y también son los distritos de mayor población que alcanza a 49932 habitantes para Chancay y 88558 para Huaral. Resaltan estos distritos por su relativo alto alfabetismo y escolaridad e ingreso. Contrariamente, los distritos de menos población y menor IDH se ubican en la sierra de la provincia entre estos resaltan Ihuari (0,5910), 27 de Noviembre $(0,6007)$ y Pacaraos que pierden población y son menos accesibles al desarrollo.

5) Provincia de Canta, con 13513 habitantes (180 ránking de población de provincias) tiene un IDH de 0,6124 , que lo ubica en el puesto 45 del ránking provincial nacional del IDH, con una esperanza de vida de 74,19 ańos, alto alfabetismo que alcanza a 
$94,65 \%$ y alta escolaridad, ingresos relativamente bajos. El distrito, que tiene mayor población y se incrementa constantemente es el de Santa Rosa de Quives, con 6173 habitantes que representa aproximadamente el $46 \%$ de la población provincial, no obstante tiene un IDH relativamente bajo de 0,6045, respecto al distrito de Canta 0,6336, sus índices de escolaridad $(90,49 \%)$ y alfabetismo $(95,81 \%)$ son relativamente altos.

6) Provincia de Huarochirí, con 72845 habitantes distribuidos en sus 32 distritos (28 ránking de población de provincias) tiene un IDH de 0,6097 que lo ubica en el puesto 46 del ránking provincial nacional del IDH, con una esperanza de vida de 71,37 ańos, alfabetismo relativamente alto que alcanza a $96,95 \%$ y alta escolaridad.

Huarochirí es una provincia de la sierra de Lima que se ubica entre las cuencas del Rímac, Lurín, Mala y muchas pequeñas cuencas que albergan a muchos distritos y que solamente Santa Eulalia con 10591 habitantes, , San Mateo con 5769 y Matucana con 4508 habitantes, son las relativamente mas pobladas en relación sus 29 distritos más, Entre los distritos de menor desarrollo humano y con bajo nivel de población se encuentran San Andrés de Tupicocha con un IDH 0,5721, Sangallaya con 0,5726 y Santiago de Anchucaya con 0,5737 de IDH

7) Provincia de Oyón, anteriormente formaba parte de la provincia de Cajatambo, actualmente tiene 20642 habitantes (170 ránking de población de provincias) tiene un IDH de 0,6040 que lo ubica en el puesto 51 del ránking provincial nacional del IDH, con una esperanza de vida de 71,89 años, alto alfabetismo que alcanza a $92,91 \%$ y alta escolaridad, ingresos relativamente bajos. El distrito que tiene mayor población entre sus 6 distritos es Oyón con 12812 habitantes que representa aproximadamente el $62 \%$ de la población provincial, no obstante tiene un IDH relativamente bajo de 0,6064 respecto al distrito de Pachangará con 0,6139, cuyos índice de alfabetismo $(94,40 \%)$ y escolaridad $(89,14 \%)$ son relativamente altos. El distrito de Oyón desarrolla como actividad económica más importante la minería, a diferencia de Pachangará que basa su economía en torno al Turismo generado por los Baños Termales de Churin y la pequeña ganadería lechera y frutícola en la cuenca del rio Huaura.
8) Provincia de Yauyos, con solo 27501 habitantes distribuidos en sus 33 distritos (156 ránking de población de provincias) tiene un IDH de 0,5848 que lo ubica en el puesto 79 del ránking provincial nacional del IDH, con una esperanza de vida de 70,17 años, alfabetismo relativamente alto que alcanza a $94,99 \%$, alta escolaridad bajos ingresos que en promedio llegan a 189,9 soles..

Yauyos, provincia de la sierra de Lima, ubicada entre las cuencas del rio Mala y rio Cañete, con muchas pequeñas cuencas. En general las poblaciones de la provincia de Yauyos, se caracteriza por su alta dispersión poblacional, en topografía de poco acceso,se ubica entre otros los distritos de menor desarrollo humano, como Chocos con un IDH 0,5444 que esta en el puesto $1356 \mathrm{del}$ IDH distrital, luego viene el distrito de Viñac con 0,5453 IDH ubicado en el puesto 1340 del ránking distrital.

9) Finalmente la provincia de Cajatambo, con sólo 8 352 habitantes (191 ránking de población de provincias) tiene un IDH de 0,5796 que lo ubica en el puesto 88 del ránking provincial nacional del IDH, con una esperanza de vida de 70,92 años, alfabetismo relativamente alto que alcanza a 89,93 $\%$, escolaridad media; bajos ingresos que en promedio llegan a 204 soles. Sus distritos que menor desarrollo humano, son Copa con 0,5414 y Gorgor con 0,5684 .

En el actual desarrollo humano de las provincias de Lima (2015) presentan las siguientes características:

a) Provincia de Huaura. con una población estimada de 213188 habitantes (23 ránking provincias) tiene un IDH de 0,5476 que lo ubica en el puesto 17 del ránking provincial del IDH, con una esperanza de vida de 77,07 años, el 72. 23\% tiene educación secundaria, alcanza a 9,92 años en promedio, y finalmente tiene un ingreso familiar de 716.1 soles. Huaura es una provincia de grandes contrastes en desarrollo humano, población, producción y urbanización. El distrito y ciudad de Huacho con 58105 habitantes alcanza un desarrollo humano de 0,6264 , le sigue el distrito de Hualmay con 0,5540 en ambos casos es menor que el año 2007. Contrariamente sus distritos de la zona de sierra como Checras $(0,2295)$, Leoncio Prado $(0,2145)$ y Ambar $(0,2399)$ muestran un 
TABLA 8

DESARROLLO HUMANO DE LAS PROVINCIAS DE LIMA 2015

EN ORDEN DE IMPORTANCIA SEGÚN IDH

\begin{tabular}{|l|c|c|c|c|c|c|}
\hline \multicolumn{1}{|c|}{ Provincia / distrito } & Población & IHD & Esperanza de vida & Educación secund \% & Años de educación & $\begin{array}{c}\text { Ingreso familiar } \\
\text { soles }\end{array}$ \\
\hline LIMA & 9395149 & 0,6340 & 78,75 & 80,90 & 10,75 & 1017.0 \\
\hline Lima & 8481415 & 0,6417 & 79,02 & 79,09 & 10,93 & 1049,2 \\
\hline REGION LIMA-PROV & 913734 & 0.5181 & 75.33 & 71.49 & 8.97 & 717.4 \\
\hline Huaura & 213188 & 0,5476 & 77.07 & 72,23 & 9.92 & 761.0 \\
\hline Barranca & 143216 & 0,5307 & 80,38 & 66.60 & 9.02 & 721.0 \\
\hline Huaral & 182409 & 0.5267 & 79.49 & 68.34 & 8.91 & 713.0 \\
\hline Cañete & 222877 & 0.5250 & 79.74 & 46.66 & 9.74 & 800.6 \\
\hline Oyón & 22217 & 0.4909 & 80.18 & 57.48 & 8.68 & 635.6 \\
\hline Huarochiri & 79177 & 0.4742 & 72.76 & 70.87 & 9.37 & 572.0 \\
\hline Canta & 14669 & 0.4405 & 75.75 & 46.92 & 8.29 & 573.1. \\
\hline Yauyos & 27842 & 0.4062 & 75.58 & 58.63 & 8.78 & 400.1 \\
\hline Cajatambo & 8139 & 0.3293 & 70.56 & 43.98 & 7.56 & 309.5 \\
\hline
\end{tabular}

Fuente: Índice de desarrollo Humano departamental, provincial y distrital 2012 PNUD

IDH mucho menor y una caída de población por la migración intensa.

b) Provincia de Barranca, con una población estimada de 143216 habitantes (40 ránking de población de provincias) tiene un IDH de 0,5307 que lo ubica en el puesto 18 del ránking provincial del IDH, con una esperanza de vida de 80,33 años, el $66.60 \%$ tiene educación secundaria, alcanza a 9,02 años en promedio y tiene un ingreso familiar de 721.0 soles por mes

c) Provincia de Huaral, con 182409 habitantes (27 ránking de población de provincias) tiene un IDH de 0,5267 que lo ubica en el puesto 20 del ránking provincial del IDH, con una esperanza de vida de 79,49 años, 68,34 \% con educación secundaria y 8.91 ańos en promedio de estudios.

Huaral es una provincia de grandes contrastes en desarrollo humano, población, producción y urbanización. Los distritos costeros de Chancay tienen una población de 57692 y un IDH de 0,6438; Huaral con una población distrital de 96 986 tiene un IDH de 0,5389. Resaltan también estos distritos por su ingreso familiar relativo alto de 739 soles. Contrariamente, los distritos de menos población y menor IDH se ubican en la sierra de la provincia, entre estos resaltan Ihuari con 2 526 habitantes y un bajo IDH de 0,2403, el distrito de Lampian con una población de sólo 460 habitantes que tiene un IDH de solo 0,2786 con baja accesibilidad respecto a otros distritos de la provincia de Huaral. d) Provincia de Cañete, con una población de 222 887 habitantes, alcanza el puesto 22 en el ránking de provincias en el país, su IDH es 0,5250 que lo ubica en el puesto 22, con una esperanza de vida de 79,74 años; la proporción de población con educación secundaria es de solamente $46.66 \%$ y el promedio de años que estudian es de 9.74 años. Los distritos que presentan mejor desarrollo humano son San Antonio con 0,56 14 IDH y Santa Cruz de Flores con 0,5158 en IDH. Los distritos de menor población y desarrollo humano se ubican en la sierra de la provincia, resaltando Coayllo con solo 1081 habitantes y un IDH bajo de 0,4915; y Pacarán con 1775 habitantes y un IDH de 0,4693.

e) Provincia de Oyón, actualmente tiene 22217 habitantes (171 ránking de población de provincias) tiene un IDH de 0,4909 que lo ubica en el puesto 37 del ránking provincial del IDH, con una esperanza de vida de 8018 ańos, (parece muy alto el dato respecto al período anterior) los estudios de educación secundaria comprende a $57.48 \%$ y el promedio de años de estudio bordea 8.68 años; sus ingresos familiares son relativamente medios que alcanzan a 635.6 soles al mes, debido a la actividad minera particularmente. El distrito que tiene mayor población entre sus 6 distritos es Oyón con 13 974 habitantes que representa aproximadamente el $63 \%$ de la población provincial, no obstante tiene un IDH relativamente bajo de 0,6064 respecto al distrito de Pachangará con 0,5215, una esperanza de vida de 79.39 años; la educación secundaria 
alcanza al 56.82 de su población y el promedio de años de estudio es de 9.10 años. El distrito de Oyón es un distrito que tiene como actividad más importante la minería que genera un ingreso relativamente alto de 748.5 soles.

f) Provincia de Huarochirí en el 2015 se estimaba con 79177 habitantes distribuidos en sus 32 distritos (78 ránking de población de provincias) con un IDH de 0,4742 que lo ubica en el puesto $45 \mathrm{del}$ ránking provincial del $\mathrm{IDH}$, con una esperanza de vida de 72.76 años, posee una escolaridad secundaria del $70.87 \%$ relativamente alta que alcanza a 96,95\% y el promedio de años de estudio alcanza 9.37 ańos; Posee un nivel de ingreso relativamente bajo de 572.3 soles.

Huarochiri, provincia de la sierra de Lima, tiene muchos mitos y leyendas expresadas en Dioses y hombres de Huarochiri: IEP 2012 traducida por J. M Arguedas. Las cuencas a donde se ubican el gran número de pueblos o distritos pequeños de Huarochiri desplegados en muchas cuencas entre las que destacan las del Rimac, Lurin, Mala y muchas pequeñas cuencas que albergan a muchos distritos y que tiene un poco más de población es Santa Eulalia con 11482 habitantes, continua San Mateo con 5222; finalmente Matucana con 4066 habitantes. Los distritos que son de menor desarrollo humano y con bajo nivel de población resaltan Cuenca con IDH 0.0946, Mariatana con 0. 2610; finalmente y Sangallaya con 0,2610 IDH.

g) Provincia de Canta, con 14669 habitantes (180 ránking de población de provincias) tiene un IDH de 0,4405 que lo ubica en el puesto 59 del ránking provincial del IDH, con una esperanza de vida de 75.75 ańos, con una población con educación secundaria que alcanza el $46.92 \%$, el promedio de años de educación es de 8.29 años y un ingreso familiar relativamente bajo que esta alrededor de 573.1 soles mensuales. El distrito que tiene mayor es Santa Rosa de Quives con 7,390 habitantes que representa aproximadamente el $50.4 \%$ de la población provincial de Canta, tiene un IDH relativamente bajo de 0,4463 respecto al distrito de Canta con 0,5206.

h) Provincia de Yauyos, con solo 27842 habitantes, que es una población similar a la de 2007 , distribuidos en sus 33 distritos (158 ránking de población de provincias) tiene un IDH de 0,4062 que lo ubica en el puesto 70 del ránking provincial del
IDH, cuenta con una esperanza de vida de 75,58 años, su población con secundaria completa representa sólo al 58, 63\%, el promedio de ańos de escolaridad alcanza 8.78 años. Finalmente, sus ingresos familiares en promedio llegan a 400.1 soles.

Yauyos es una provincia de la sierra de Lima que se ubica entre las cuencas del rio Mala y rio Cañete con muchas pequeñas cuencas que albergan a muchos pequeños pueblos y distritos. En general las poblaciones de la provincia de Yauyos tienen un bajo nivel de concentración y alta dispersión poblacional en topografía de poco acceso, se ubican entre otros los distritos de menor desarrollo humano como Chocos con un IDH 0,2404 que se ubica en el puesto 1378 del IDH distrital, luego viene el distrito de Madean con 0,2305 IDH y que se ubica en el puesto 1459 del ránking distrital.

i) Finalmente tenemos la provincia de Cajatambo, que es la provincia con menor población que pierde población de manera permanente, actualmente cuenta con sólo 8139 habitantes (192 ránking de población de provincias) tiene un IDH de 0,3293 que lo ubica en el puesto 109 del ránking provincial del IDH, su esperanza de vida de 70,56 años, la población con educación secundaria es de 43.98 años, los años promedio de educación de poblaciones de mas de 25 años es de 7,56 ańos. La provincia observa bajos ingresos que en promedio llegan a 309.5 soles . Los distritos que menor desarrollo humano manifiestan son Gorgor con 0,2392 IDH y Copa con 0,2471 .

\section{Conclusiones}

El presente estudio nos ha permitido arribar a las conclusiones que a continuación se detallan:

1. La desigualdad territorial, la pobreza rural principalmente andina y la enorme diferencia de ingresos medidos, a través de los niveles socioeconómicos, durante estas tres últimas décadas, se han agravado en el ámbito nacional y en particular en el escenario de las provincias de mayor ruralidad, respecto a las provincias costeras de la Región Lima-Provincias. Las diversas formas de desigualdad limitan el desarrollo social, la democracia y baja movilidad social manteniendo una estructura social con enormes brechas de ingreso. 
2. La intensificación de la migración de las y los jóvenes, desde los ańos setenta del pasado $S$ XX hasta la actualidad, de las poblaciones de las provincias andinas de Cajatambo, Oyon , Huaura, Canta, Chancay, Huarochirí y Yauyos, que conservan y reproducen la cultura rural ancestral a través de la difusión de conocimientos y tecnicas de parte de las y los adultos mayores, quienes conservan sus rasgos étnicos y en menor proporción los rasgos lingüísticos. La economía agricola, ganadera campesina tradicional, de pequeñas empresas agrícolas y de agricultura de subsistencia de baja productividad, constituyen factores que impulsan el flujo migratorio a las ciudades de Lima, Barranca, Huacho, Huaral y Cañete. Estas ciudades receptoras de la migración especialmente e Cańete y Barranca se ubican como las más violentas y peligrosas, ocupando el $2^{\circ}$ y $3^{\circ}$ lugar en el ránking nacional de violencia, después de Tumbes, con 30 y 25 asesinatos por 100 mil el 2014.

3. El centralismo limeño actual, generado y fortalecido por el modelo extractivista y neoliberal vigente, ha acentuado y /o mantenido las desigualdades territoriales, las desigualdades de ingreso, las desigualdades de género y étnico raciales. Ha generado e intensificado la segregación espacial dando lugar por "seguridad"a la implementación de fronteras inaccesibles de espacios públicos como el ya famoso y polémico muro que separa ricos y pobres en Lima difundido por Pierina Pighi de la BBC Mundo -22 octubre 2015- . El denominado "el muro de la vergüenza” es según otros simplemente una respuesta a la inseguridad: se trata de muro de 10 kilómetros de largo construido en Lima, que separa a una de las urbanizaciones más ricas de la ciudad de una de las zonas más pobres, que paradójicamente comparten dos lados de un mismo cerro." expresión visible de un aprtheid de segregación espacial de barrios en situación de pobreza extrema.

4. Las migraciones y el incremento de asentamientos urbanos, en las provincias de Barranca, Chancay, Huaral y Cańete que impulsan una agricultura comercial y de exportación, agudizan la precariedad del empleo e ingresos de sus trabajadores y trabajadoras (que no alcanza a los 30 soles diarios) y en muchos casos mantienen formas de explotación etnico racial y de género, pero aparecen como exitosas y de "pleno empleo".
5. Respecto a la Región Lima-Provincias, podemos observar dos tendencias: la primera, ubicada en la zona de mayor concentración y consolidación de las provincias y centros urbanos ubicados en el litoral como Barranca, Huacho y Cañete que en conjunto representan el 64\% de la población regional; la segunda, ubicada en la zona andina de Lima que generan altas tasas de migración especialmente de poblaciones jóvenes que provienen de Cajatambo, Canta, Oyón, Huarochirí y Yauyos que en conjunto participan sólo del $17 \%$ de la población de la Región Lima.

\section{Referencias bibliográficas}

Altamirano, Teófilo (2009). Migración, remesas y desarrollo en tiempos de crisis. Lima: Unfpa, PUC CISEPA.

APEIM (2014). Niveles socioeconómicos 2014. Lima: Apeim. Arellano, Rolando (2010) Al medio hay sitio.

BBC Mundo (2015a). El polémico muro que separa a ricos y pobres en Lima. Pierina Pighi http://www.bbc.com/ mundo/noticias/2015/10/151019_peru_muro_barrio_ pobre_rico_lima_amv

BBC Mundo (2015b). Lima, la ciudad de América Latina donde los pobres pagan diez veces más por el agua. John Mervin BBC http://www.bbc.com/mundo/noticias/2015/10/151009_economia_desigualdad_agua_ lima_lf

Caritas Huacho (1998). Diagnóstico de la provincia de Barranca, Huacho.

Cepal (2010). La hora de la igualdad: brechas por cerrar. Santiago de Chile: Cepal.

Cepal (2015). Desarrollo social inclusivo. Santiago de Chile: Ediciones Cepal.

Ceplan (2011). Plan Bicentenario. El Perú hacia el 2021. Lima: CEPLAN.

Cerrón-Palomino, Rodolfo (2008). Voces del Ande. Lima: Fondo Editorial de la Universidad Católica del Perú.

Contreras, Carlos (2002). Centralismo y descentralismo en la historia del Perú independiente. JCAS/IEP.

Dammert, Manuel (2012). Territorialidad y descentralización de la gestión pública. En: Perú hoy: Lo urbano en lo rural. Lima: Desco.

Desco (2010). Perú hoy. Centralismo y descentralización. Lima: Desco.

Durand, Francisco (2007). El Perú fracturado. Formalidad, informalidad y economía delictiva. Lima: Fondo Editorial del Congreso del Perú. 
García, María Elena (2008). Desafíos de la interculturalidad. Lima: IEP.

Golte, Jürgen (2012). Migraciones o movilidad social desterritorializada en Carlos Degregori, Pablo Sandoval y Pablo Sendón, No hay país más diverso, IEP.

Gonzales de Olarte, Efrain (2010). Descentralización por el desarrollo humano, PNUD Perú.

Huertas, Lorenzo (1981). La religión en una sociedad Rural Andina Siglo XVII, UNSCH, Huamanga.

INEI (2007). Sistema de consulta de indicadores de pobreza a nivel de distrito, $\mathrm{CD}$.

INEI (2009). Perfil Sociodemográfico de la Región Lima.

INEI (2011). Perfil de la pobreza según departamentos, 20012010.

INEI (2013). Población y territorio. Lima: INEI.

INEI (2014). Informe Técnico: Evolución de la pobreza monetaria 2009-2014: Lima.

INEI (2015). Mapa de pobreza provincial y distrital 2013.

INEI (2015). Brechas de género.

INEI (2015). Mapa de pobreza provincial y distrital 2013. Lima: Ediciones INEI UNFPA.

Matos Mar, José (2012). Perú: Estado desbordado y sociedad nacional emergente. La historia corta del proceso peruano: 1940-2010. Lima, URP.

Miranda Valdivia, Franklin (2011). Cajatambo: tradición, quechua y desintegración regional. En: Investigaciones sociales Vol. 15, № 26 175-211. Lima: UNMSM.

Miranda Valdivia, Franklin (2015). La descentralización centralista en el Perú: entre la crisis y el crecimiento 1970-2014. En: Investigaciones Sociales Vol. 19, No 34 153-163. Lima: UNMSM.

Monge, Carlos (2012). Lo rural y lo urbano en el Perú de hoy. En: Perú hoy: Lo urbano en lo rural. Lima: Desco.

Montoya Rojas, Rodrigo (2010). Porvenir de la cultura quechua en Perú. Lima: OXFAM, CONACAMI, UNMSM.
Murra, John (2009). El mundo andino. Lima: IEP.

OXFAM (2016). Agenda contra la desigualdad: cinco temas críticos para cerrar las brechas. Documento de trabajo 2, Lima.

OXFAM (2014). Informe. Gobernar para las elites.

OXFAM (2016). Agenda contra la desigualdad.

PCM-USAID (2011). Planificación descentralizada para conducir el desarrollo. Lima: USAID.

Piketty, Thomas (2014). El capital en el Siglo XXI. México D.F.: Fondo de Cultura Económica.

PNUD (2003). Informe Desarrollo Humano, Perú 2002.

PNUD (2009). Población: las cuencas articulan la convivencia. En: Informe sobre desarrollo. Lima: PNUD.

PNUD (2010). Informe sobre desarrollo Humano.

PNUD (2011). Informe Regional sobre Desarrollo Humano.

PNUD (2012). Indice de desarrollo humano departamental, provincial y distrital 2012. Lima.

PNUD (2013). Autopercepciones de la población afroperuana: identidad y desarrollo. Panamá: PNUD.

Polastri, Rossana y Fernando Rojas (2008). Descentralización en Perú: Oportunidad de un país diferente.

Proeduca GTZ (2004). Los castellanos del Perú, DVD. Lima. PUCP TVCultura (2008). Las lenguas del Perú, DVD, Lima.

Pulgar VIdAL, Javier (1979). La regionalización transversal. Lima: CIUP.

Rostworowsky, María (1988). La mujer en la época prehispánica. Lima: IEP Documento de Trabajo 17.

Thorp, Rosemary y Maritza PARedes (2011). La etnicidad y la persistencia de la desigualdad. El caso peruano. Lima: IEP.

Torres, Alfredo (2013). 25 años de niveles socionómicos. Percepciones y realidades. En: Semana Económica, p.10. Lima.

UniCeF (2015). Estado de la niñez en el Perú. Lima: UNICEF. 